\title{
Cone penetration test in assessment of soil stiffness
}

\author{
Wojciech TSCHUSCHKE ${ }^{1}$, Maciej Kordian KUMOR ${ }^{2}$, Magdalena WALCZAK ${ }^{1, *}$ and Marcin TSCHUSCHKE ${ }^{3}$ \\ 1 University of Life Sciences, Department of Geotechnics, Wojska Polskiego 28, 60-637 Poznań, Poland \\ 2 University of Technology and Life Sciences, Department of Geotechnics, Kordeckiego 20, 85-225 Bydgoszcz, Poland \\ 3 Consoil Project Ltd., Kunickiego 19, 61-418 Poznań, Poland
}

Tschuschke, W., Kumor, M.K., Walczak, M., Tschuschke, M., 2015. Cone penetration test in assessment of soil stiffness. Geological Quarterly, 59 (2): 419-425, doi: 10.7306/gq.1188

The paper presents proposals for the assessment of subsoil stiffness based on results of the seismic cone penetration test. Correlations between penetration parameters and constrained modulus were determined for three genetically different groups of cohesive soils. For the analysed soil material, quantitative estimation was also conducted for the parameter determining the relationship between the constrained modulus and initial shear modulus. A marked trend was shown for this parameter with the soil behaviour type index used in the classification of soils in the cone penetration test.

Key words: soil stiffness, seismic cone penetration test (SCPTU), cohesive soils.

\section{INTRODUCTION}

For a long time a key role in geotechnical site characterization has been played by the cone penetration test (Lunne et al., 1997; Robertson, 2001; Sikora, 2006; Mayne, 2007). The spectacular advance leading to the current position of this test has obviously stemmed from its advantages, particularly such as universality and rapid performance, reliability and repeatability of the results, as well as the performance of this test under specific stress and drainage conditions (Lunne et al., 1997; Robertson, 2001). Most geotechnical properties including physical, mechanical, filtration and state parameters may be determined on the basis of interpretation procedures analyzing penetration curves from this test (Lunne et al., 1997; Sikora, 2006). In the hierarchy of assessment reliability, the greatest ambiguities seem to be associated with the estimation of subsoil deformation parameters. Testing conditions in the cone penetration test differ significantly from those, under which the preference calibration tests are conducted. Thus, the solutions applied in practice are typically based on empirical relationships, frequently local in character (Robertson, 2001; Mayne, 2007). When solving this problem, it may be very helpful to include measurements of seismic wave velocity to the piezocone test (Atkinson, 2000; Jamiolkowski, 2012). Based on the theory of elasticity, we may in such a case determine subsoil deformation parameters both

* Corresponding author, e-mail: mwalczak@up.poznan.pl

Received: December 4, 2013; accepted: May 5, 2014; first published online: August 29, 2014 at very small and large strains. Knowledge on the relationships between constrained moduli provides additional information on subsoil stiffness (Mayne, 2007).

\section{LOCATION AND OBJECT OF ANALYSES}

The testing site is located in southwestern Poland, at the construction site of a wind farm comprising foundations of 80 wind turbines with towers of $80 \mathrm{~m}$ in height (Fig. 1). The design predicts shallow circular foundations of $20 \mathrm{~m}$ in diameter for the wind turbines. For each object it is planned to drill one borehole completed with sampling, one cone penetration test (CPTU) and one test using a seismic cone (SCPTU). The assumed required depth of subsoil identification was at least 1B, i.e. $20 \mathrm{~m}$, assuming the arrangement of testing points at the vertices of an equilateral triangle inscribed into a circle, also being the outline of the designed foundation plate. Due to the character of the structure and the subsoil - foundation interaction, particularly thorough analysis had to be performed to determine subsoil deformation parameters for both very small and large strains being a result of both static and dynamic loads.

In terms of morphology, the study area is a flat post-glacial plateau formed as a result of erosion and denudation processes. In terms of the origin of soils in the subsoil, they are greatly varied in their degree of preconsolidation. Three genetically different groups of cohesive soils were selected, typical of the investigated area. The groups comprised (1) older, bluish-grey Neogene clays, (2) grey-brown sandy tills and glaciofluvial tills, and (3) grey-blue lessive silty clays. The characteristic grain size distribution of the soil groups is presented in Figure 2. 


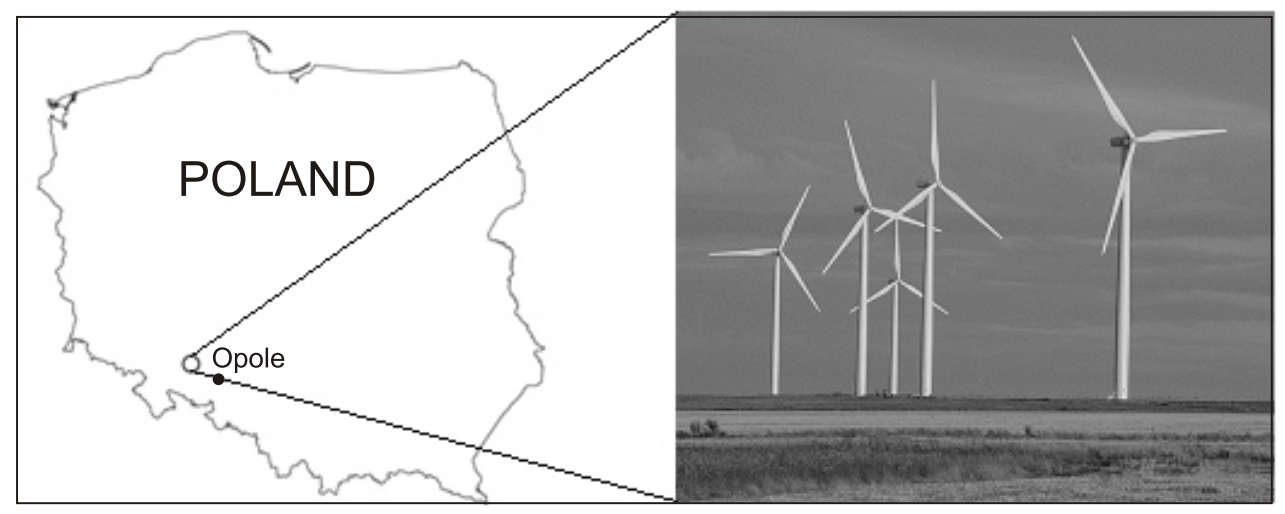

Fig. 1. Location of the research area

\section{INTERPRETATION OF CONE PENETRATION TESTING DATA}

The penetration characteristics recorded in the cone penetration test include distribution with depth of the following parameters: cone resistance $q_{c}$, friction on the sleeve $f_{s}$ and excess pore pressure $u_{c}$, which is specified by the determination of filter location on the cone. Most frequently, pore water pressure is measured with a filter located behind the cone $u_{2}$ (Lunne et al., 1997; Mayne, 2007). All characteristics are recorded in a quasi-continuous manner, at every $2 \mathrm{~cm}$ increment in penetration depth. As a result of stopped cone penetration, the test of excess pore pressure dissipation is initiated (Burns and Mayne, 2002). Interpretation procedures for cone penetration test results usually require standardization and normalization of the recorded test parameters to the following forms:

- corrected cone resistance $q_{t}$

$$
q_{t}=q_{c}+(1-a) u_{2}
$$

- friction ratio $R_{f}$

$$
R_{f}=\frac{f_{s}}{q_{t}} 100 \%
$$

- pore pressure parameter $B_{q}$

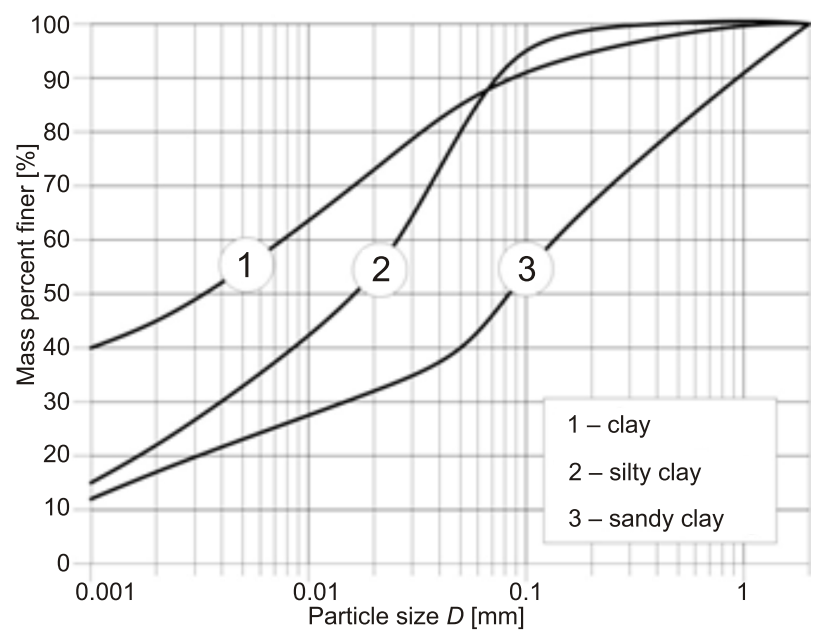

Fig. 2. Grain size distributions of the cohesive soils

$$
B_{q}=\frac{u_{2}-u_{0}}{q_{t}-\sigma_{v 0}}
$$

where: $a-$ net area ratio of the cone, $u_{0}-$ in situ pore pressure, $\sigma_{\mathrm{v} 0}-$ total overburden stress.

These indexes are used in the identification of soil behaviour type in the CPTU classification systems (Jefferies and Davies, 1993; Robertson, 2001, 2009). Moreover, the pore pressure parameter is used in the assessment of drainage conditions in the penetrated soil layer. The type of soil behaviour may be defined quantitatively based on the cone soil classification index $I_{C}$, which generalizes its assessment through three normalized parameters for: tip resistance $Q$, friction $F$, and pore pressure $B_{q}$.

$$
I_{C}=\sqrt{\left[3-\log \left[Q \cdot\left(1-B_{q}\right)\right]\right]^{2}+[1.5=1.3(\log F)]^{2}}
$$

$$
Q=\frac{q_{t}-\sigma_{v 0}}{\sigma_{v 0}^{\prime}}
$$

$$
F=\frac{f_{s}}{q_{t}-\sigma_{v_{0}}} \cdot 100 \%
$$

where: $\sigma_{\mathrm{v} 0}^{\prime}-$ effective overburden stress.

The assessment of soil deformation parameters based on the penetration parameters is much more complicated due to the observed mechanism of failure under the cone, which is accompanied by considerable displacement of soil around the cone and the need to estimate drained consolidation from an undrained penetration test. For this reason, the deformation parameter, defined as the one-dimensional constrained modulus $(M)$ and measured in an oedometer test is estimated based on cone resistance. As such, it is used solely as an empirical relationship, which is limited to a simple formula (Arroyo, 2013; Burns and Mayne, 2002; Mayne et al., 2003).

$$
M=\alpha_{c}\left(q_{t}-\sigma_{v 0}\right)
$$

where: $\alpha_{c}$ - empirical factor.

Analysis of literature on the subject shows that the value of empirical factor is not constant and for normal soils it may change from $\alpha_{c}=0.4$ for peat and organic clay to for cemented 
clay (Lunne et al., 1997; Mayne, 2007). Appropriate estimation of the empirical factor, with local experience in the individual site-specific and area-specific correlations, can be developed for certain soil types with greater reliability (Lunne, et al., 1997; Sikora, 2006).

Incorporation of measurements of seismic wave velocity SCPTU to piezocone testing, apart from the estimation of the constrained modulus at strains $\varepsilon \approx 10^{-1}$, also facilitates a much more accurate determination of the initial shear modulus $G_{0}$ and equivalent elastic Young's modulus $-E_{0}$ applies strictly to the nondestructive range of shear strains $-\gamma_{s}<10^{-6}$ (Mayne et al., 2003; Jamiolkowski, 2012; Kim et al., 2013). This stiffness applied to the initial loading for all stress-strain-strength curves, including static, cyclic and dynamic types of loading, under drained and undrained conditions (Mayne, 2007). The small-strain soil stiffness is calculated from the soil mass density $\rho$, and shear or compression wave velocity $V_{S}$ or $V_{p}$.

$$
\begin{aligned}
& G_{0}=\rho \cdot\left(V_{S}\right)^{2} \\
& E_{0}=\rho \cdot\left(V_{p}\right)^{2}
\end{aligned}
$$

where: $V_{S}$ - velocity of shear wave, $V_{p}$ - velocity of compressive wave.

If there are no independent measurements of the soil mass density, the value of this parameter may be estimated indirectly on the basis of the empirical relationship between normalized shear wave velocity and saturated unit weight $\gamma_{\text {sat. }}$ (Mayne, 2006).

$$
\begin{gathered}
\gamma_{\text {sat. }}=4.17 \ln \left(V_{s 1}\right)-4.03 \\
V_{s 1}=\frac{V_{s}}{\left(\sigma_{v 0}^{\prime} / \sigma_{a t m .}\right)^{0.25}}
\end{gathered}
$$

where: $V_{S 1}-$ normalized shear wave velocity, $\sigma_{a t m}-$ atmospheric pressure.

Assessment of soil stiffness under small-strain conditions may be supplemented with the determination of the value of Poisson's ratio $(v)$, which may formally be written in the function of recorded seismic wave velocities.

$$
v=\frac{1}{2}\left[1-\frac{1}{\left(V_{p} / V_{S}\right)^{2}-1}\right]
$$

All the three constant elasticity values determined on the basis of seismic measurements are a perfect extension of the constrained modulus, which in contrast is estimated from the analysis of cone resistance.

\section{METHODS AND RESULTS}

Analyses of rigidity of soils from the subsoil of the area of the designed wind farm were conducted on the three selected, genetically different series of cohesive soils, whose characteristic grain size distributions are presented in Figure 2. Apart from genetic variation, each isolated group of soils is distinguished by a different dominant fraction, i.e. in group I (clays) - the clay fraction, in group II (silty clays) - the silt fraction, in group III (sandy clays) it is the sand fraction. Results of cone penetration tests in two example profiles are presented in Figures 3 and 4. It results from a review of cone penetration test results: the groups of cohesive soils are found in different zones of the entire subsoil. This fact influences the normalization of penetration parameters using the appropriate state of stress, related to deposition depth of the layer. In terms of the general assessment, the analysed layers may be described by the following indicator penetration parameters:

- clays: $B_{q}<0 ; R_{f} \approx 6.2 \%$,

- silty clays: $B_{q} \leq 0 ; R_{f} \approx 4.1 \%$,

- sandy clays: $B_{q} \geq 0 ; R_{f} \approx 2.8 \%$.

Assessment of soil behaviour type based on a cone soil classification index [equation 4] identified analysed soils in the group of: clays $\left(I_{C}=3.15\right)$, silt mixtures $\left(I_{C}=2.80\right)$ and sand-silt mixtures $\left(I_{C}=2.68\right.$; Jefferies and Davies, 1993; Robertson, 2009). In order to obtain a reliable solution in the analysis of testing results, it was necessary to limit sources of the most significant measurement uncertainties. The first, associated with the quality of collected oedometric soil samples and determination of a representative value of the constrained modulus from the compressibility curve, was solved thanks to the application of the Osterberg sampler in the collection of cohesive soils, while the the constrained modulus value was determined from the compressibility curve for vertical effective stress corresponding to in situ effective overburden stress (Fig. 5; Atkinson, 2000). A potential, second source of measurement uncertainty was related to the natural heterogeneity of subsoil structure, which had to be included in the selection of representative soil parameters used in the construction of correlation relationships. Samples of $20 \mathrm{~mm}$ in height were collected for laboratory analyses, penetration parameters were estimated as means from a $10 \mathrm{~cm}$ thick layer, while in seismic tests, the analysed layer is 1 $m$ thick (Tschuschke et al., 2013). The qualification criterion for testing results was homogeneity, stated on the basis of analyses of changes in cone resistance and the friction ratio in the layer structure in a zone of at least $1 \mathrm{~m}$ in thickness, corresponding to the measurement intervals of seismic wave velocity. Homogeneity of soil in the analysed layer was again verified on the basis of macroscopic analysis of undisturbed samples.

\section{ANALYSIS OF TESTS RESULTS}

Statistical analysis of in situ and laboratory testing results consisted of three parts. The first stage was an attempt to determine the correlation [equation 7] between the modulus determined in the oedometric test for effective vertical stress, which corresponds to effective overburden stress, determined for the depth of the profile from which the sample was collected, and net cone resistance normalized by the value of total overburden stress for the corresponding sampling depth in the subsoil zone. The analysis was conducted independently for each of the three isolated groups of cohesive soils. Results of the analysis are presented in Figure 6.

They make it possible to formulate the following conclusions. Firstly, it was confirmed that the analysed data belong to three statistically different samples, as indicated by the grain size criterion. Secondly, for each group of deposits, different regression coefficients $\alpha_{c}$ were determined for the correlation relationship expressed in equation [7]. Estimated regression coefficients have the following values:

- for clays $(i):\left(f_{i}>30 \%\right) ; \alpha_{c}=8.19$,

- for silty $(\pi)$ clays: $\left(f_{i}<30 \%, f_{\pi}>50 \%\right) ; \alpha_{c}=9.57$,

_ for sandy (p) clays: $\left(f_{i}<30 \%, f_{p}>50 \%\right) ; \alpha_{c}=10.57$. 

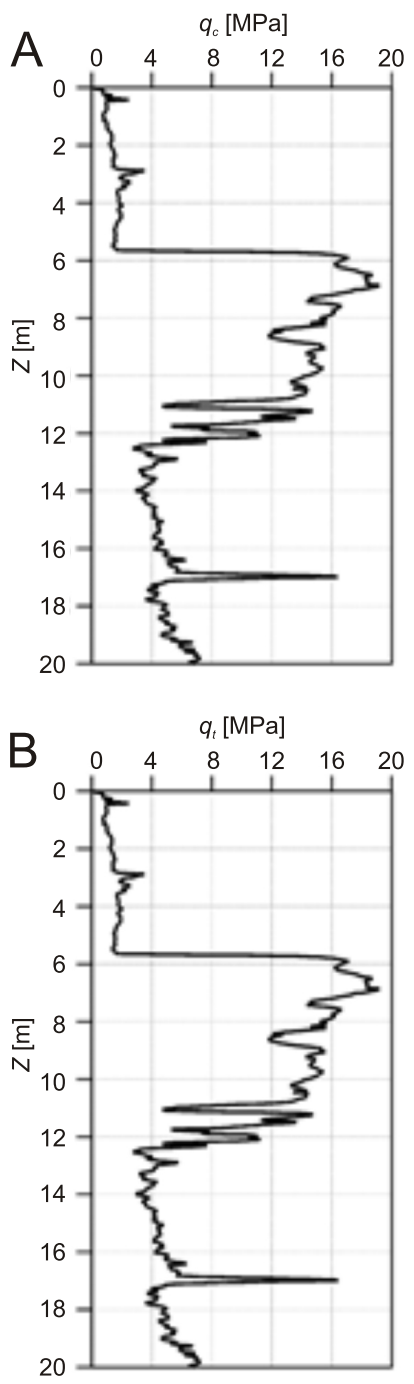

$V_{s}, V_{p}, V_{s l}[\mathrm{~m} / \mathrm{s}]$

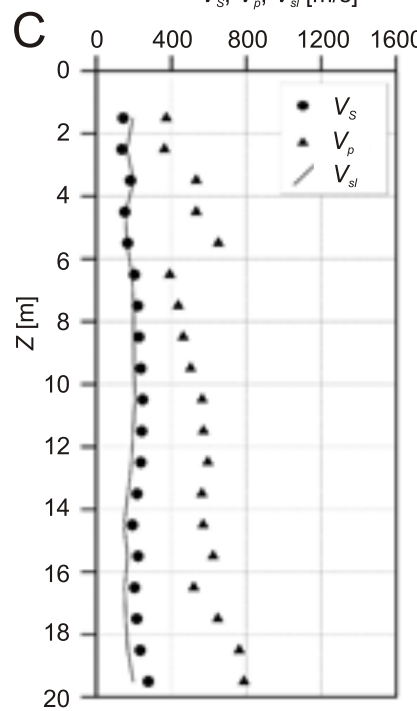

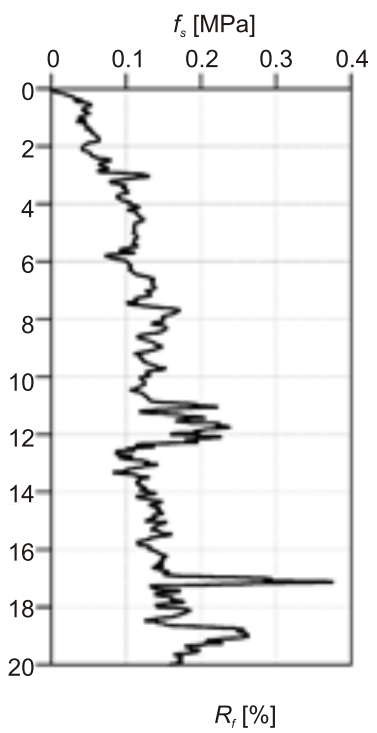

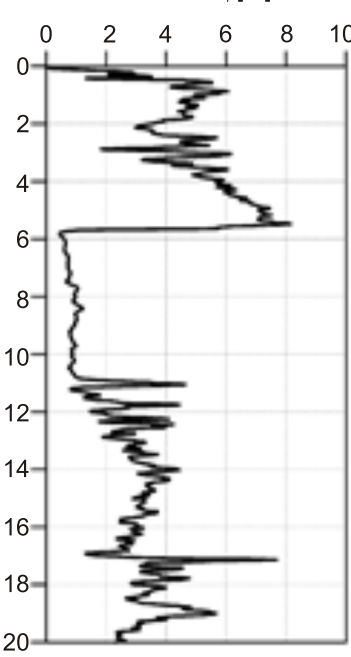

$G_{0}, E_{0}[\mathrm{MPa}]$

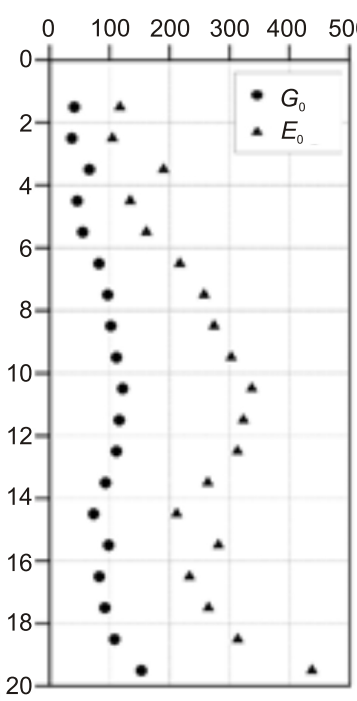

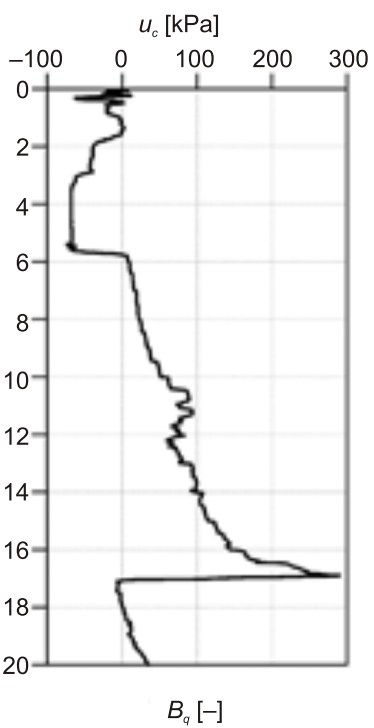

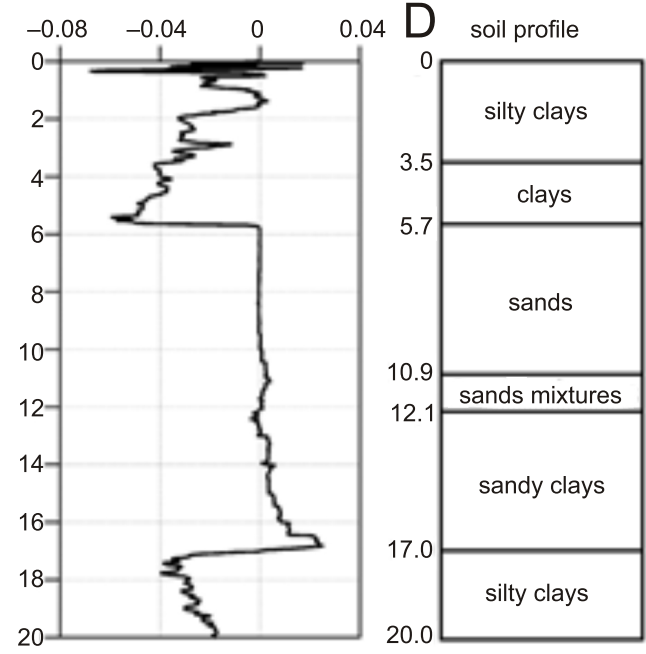

$\vee[-]$

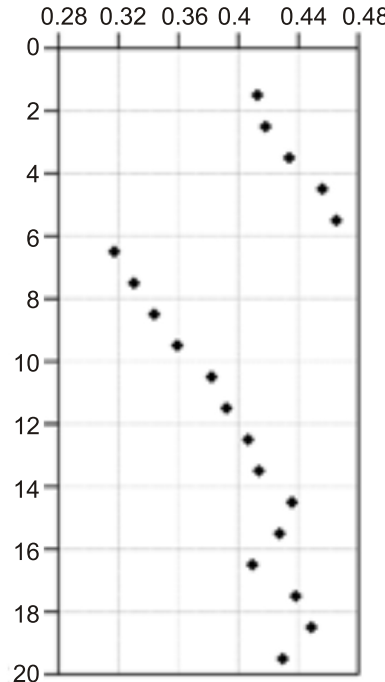

Fig. 3. Results of seismic cone penetration test at testing point no. 17

A - parameters recorded, B - normalized, C - seismic, D - soil profile 

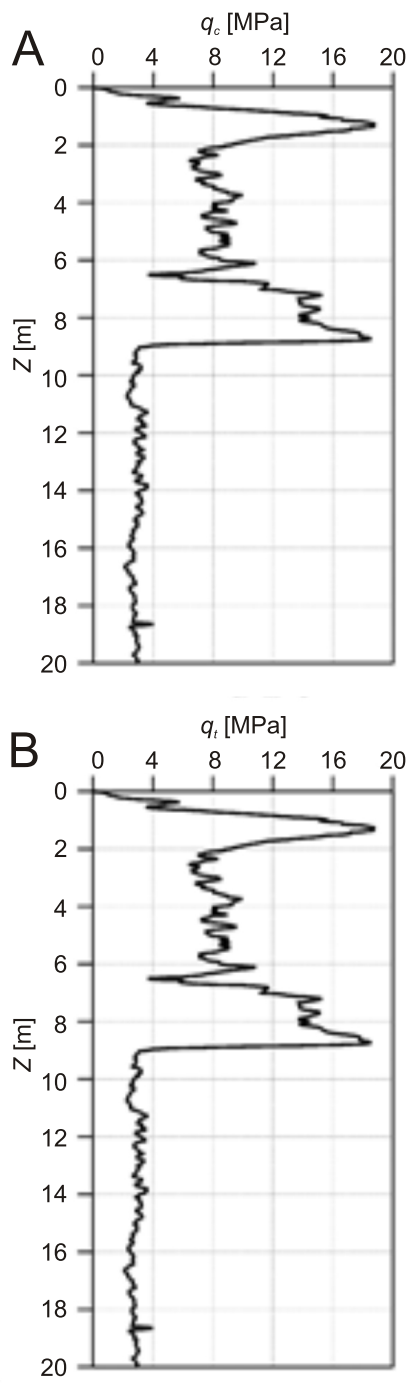

$V_{s}, V_{p}, V_{s l}[\mathrm{~m} / \mathrm{s}]$

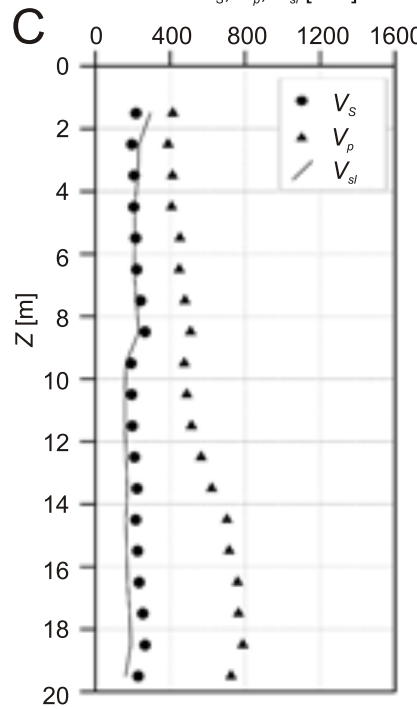

$f_{s}[\mathrm{MPa}]$
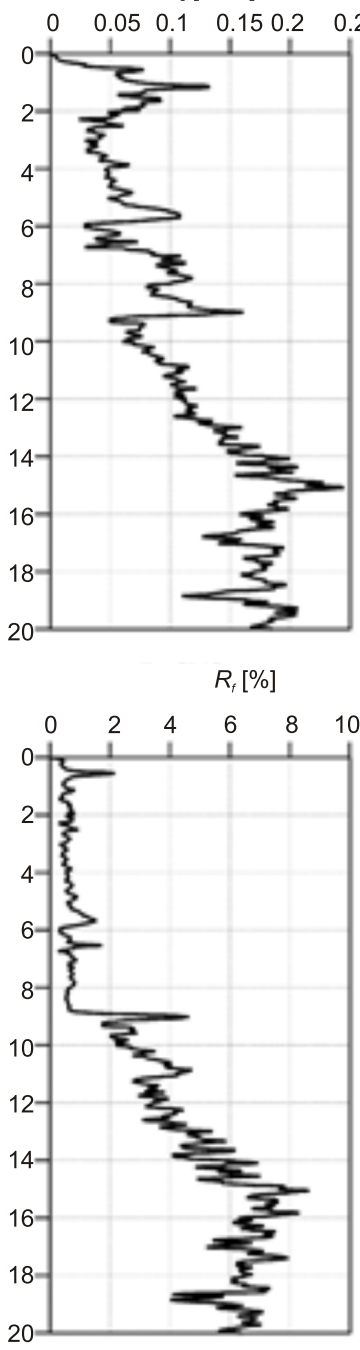

$\mathrm{G}_{0}, E_{0}[\mathrm{MPa}]$

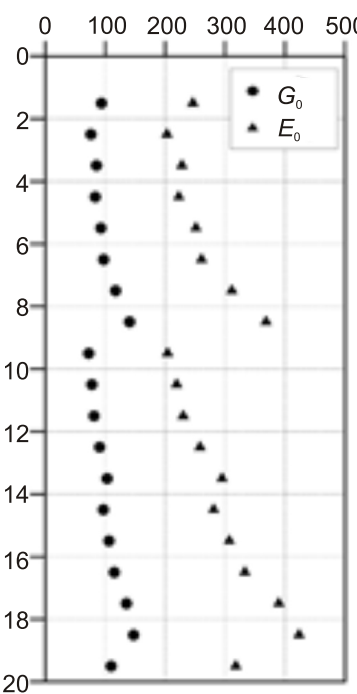

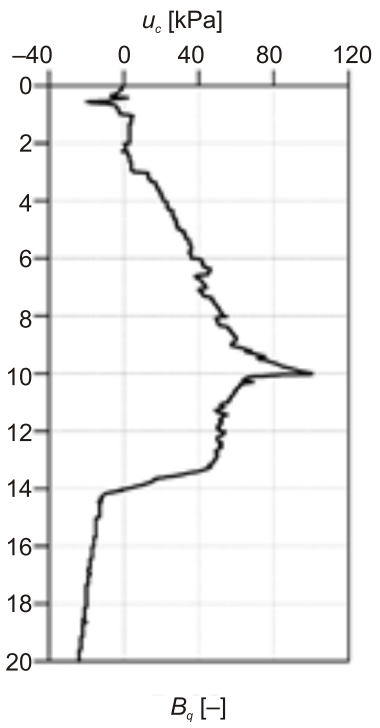

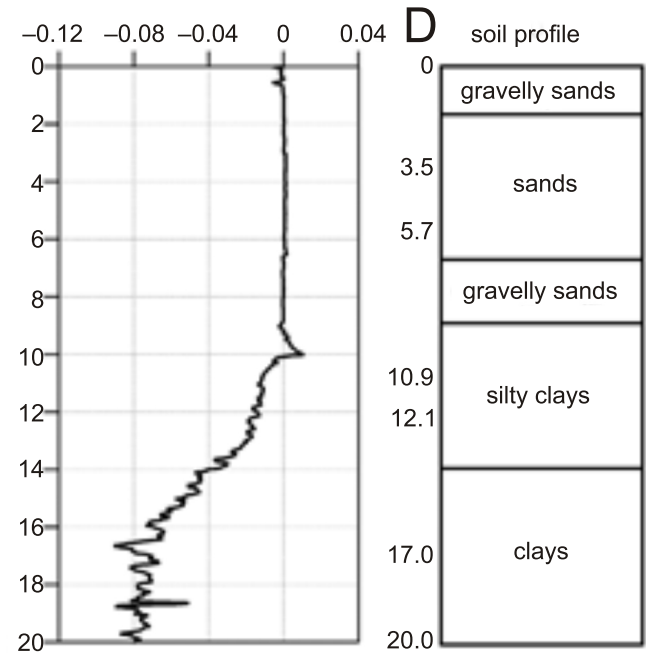

v [-]

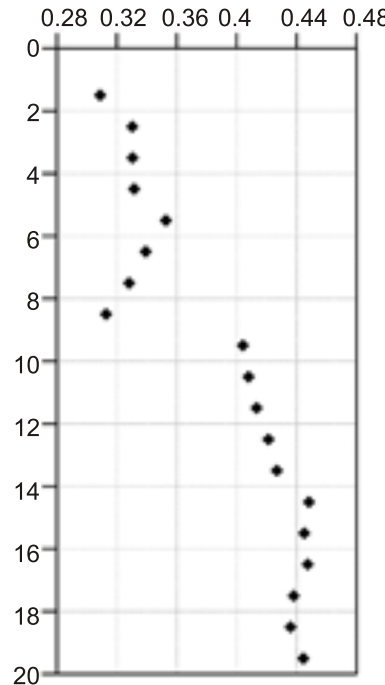

Fig. 4. Results of seismic cone penetration test at testing point no. 25

A - parameters recorded, B - normalized, C - seismic, D - soil profile 


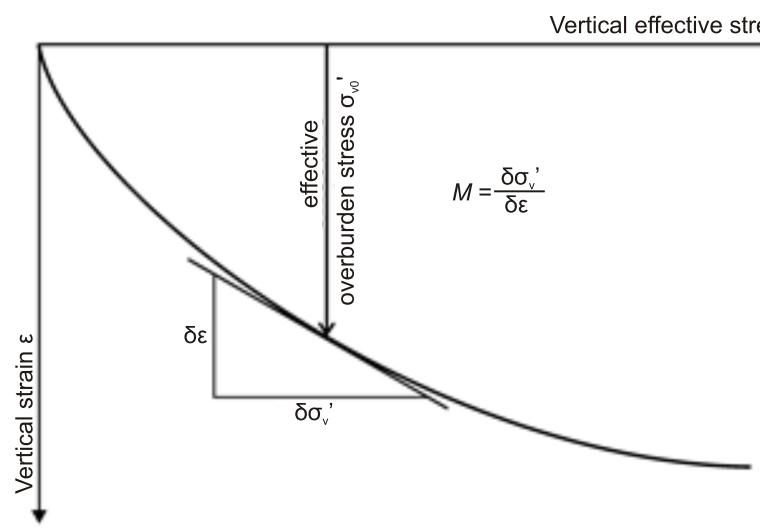

Fig. 5. Interpretation of constrained modulus from oedometric test

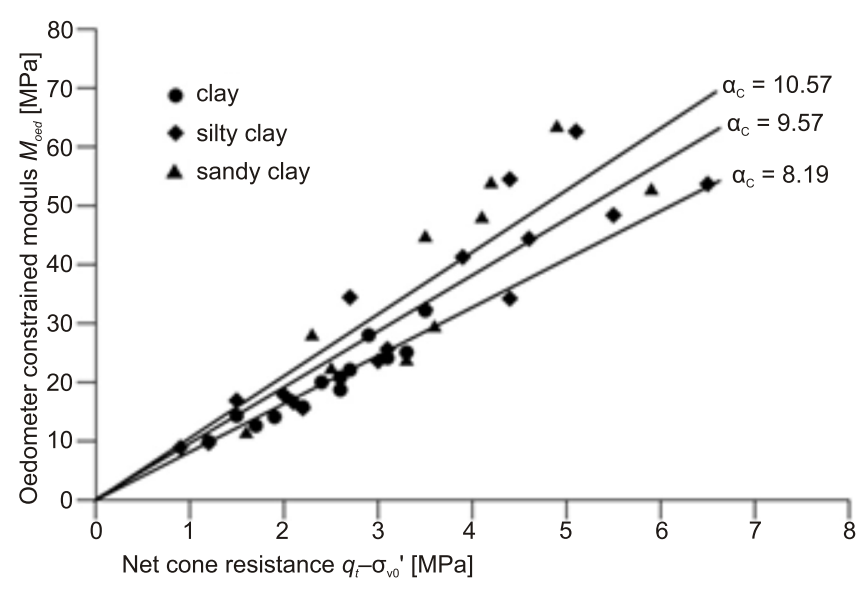

Fig. 6. The relationship between oedometer constrained modulus and net cone resistance for the cohesive soils

Thirdly, a marked consistency was found between the macroscopic assessment of homogeneity of soil samples and the measure of variability in the distribution of variables. The observed empirical relationships are characterized by the following statistical coefficients of determination $r^{2}$ at sample size $n$ :

- for clays: $r^{2}=0.89 ; n=13$

- for silty clays: $r^{2}=0.85 ; n=17$,

- for sandy clays: $r^{2}=0.74 ; n=10$.

In the second stage of analyses, the significance of the correlation was verified between constrained modulus (estimated on the basis of cone resistance) and initial shear modulus (determined from the measured shear wave velocity and two measurements taken during the same SCPTU) within the isolated stratigraphic unit of the subsoil. Such a relationship for the three groups of cohesive soils is shown in Figure 7 and expressed by:

$$
\alpha_{G}=\frac{M}{G_{0}}
$$

Like in the previous analysis, in this one we also observe a variation in the trend line for the analysed groups of cohesive soils. Both the smallest slope of the trend line and statistically the most advantageous estimation was obtained for clays, while the greatest slope of the trend line accompanied by the weakest correlation was found for sandy clays. The results of statistical analysis for the three groups of cohesive soils in the

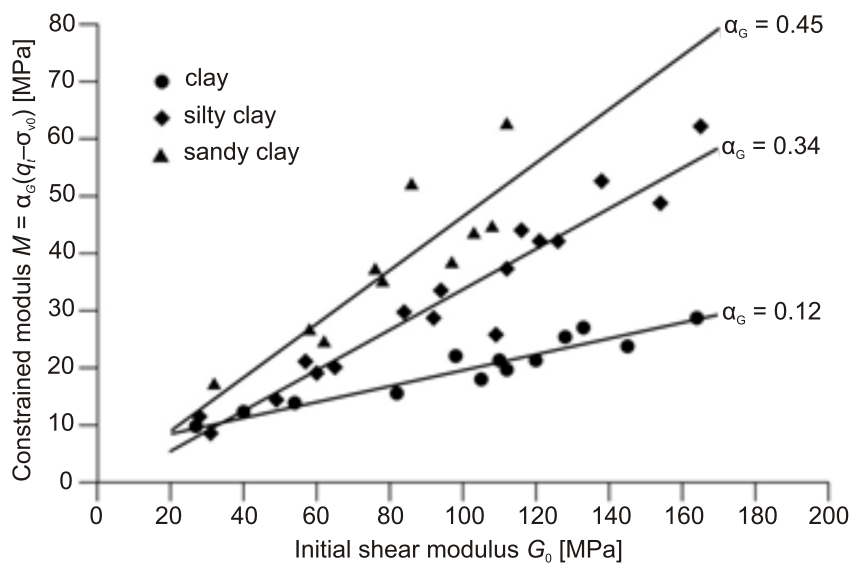

Fig. 7. The relationship between constrained modulus and initial shear modulus for the cohesive soils

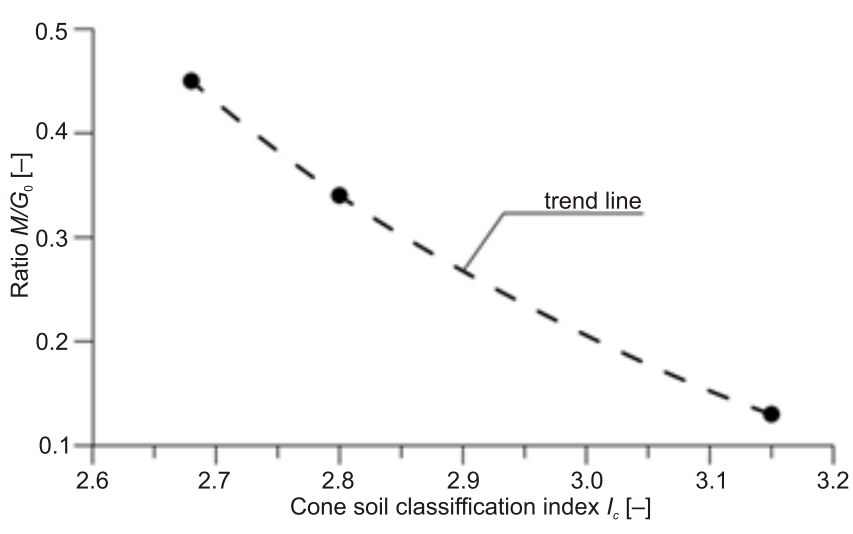

Fig. 8. The relationship between coefficient and cone soil classification index for the cohesive soils

range of estimated variation in deformation parameters are as follows:

- for clays: $\alpha_{G}=0.13 ; r^{2}=0.93 ; n=13$,

- for silty clays: $\alpha_{G}=0.34 ; r^{2}=0.89 ; n=17$,

- for sandy clays: $\alpha_{G}=0.45 ; r^{2}=0.77 ; n=10$.

The last, third element of the statistical analysis was to show a relationship between the soil type and values of parameter $\alpha_{G}$, which is an indicator between moduli determined at large and small deformations. The cone soil classification index was used to identify the soil type based on penetration parameters [equation 4]. The relationship between the parameters of soil classification and rigidity is shown in Figure 8. The insufficiently numerous statistical sample prevented a reliable statistical assessment; however, testing results document a marked upward trend for coefficient $\alpha_{G}$ with a decrease in values of coefficient $I_{c}$. Supplementation of this analysis with other types of soils, of different origin, would make it possible to verify the hypothesis on the significance of such a relationship in a statistically unambiguous manner.

\section{CONCLUSIONS}

The seismic cone penetration test (SCPTU) may prove particularly useful in geotechnical analyses, in which the assessment of soil stiffness is a key research problem. In the assumptions for this analysis, it is possible - based on cone resistance 
and seismic wave velocity - to determine characteristics of subsoil deformation both at large and very small strains. In the former, simple empirical relationships are used, whose reliability depends on the accuracy of selection of the regression coefficient, while in the latter, theoretical dependencies are used. Analysis of testing results, covering three different groups of cohesive soils, shows that an indirect identifier of soil stiffness may be provided in CPTU by the soil behaviour type index, based on which we may estimate values of parameters used in the assessment of constrained modulus on the basis of net cone resistance and the relationship between constrained modulus and initial shear modulus. Knowledge of these relationships on the one hand makes it possible to supplement results of incomplete tests, while on the other hand it constitutes a useful method to control the quality of cone penetration test result interpretation. Although the empirical relationships presented in this study are local in character, related to the testing site and specific character of the analysed soils, they indicate clearly the trends of dependencies and, in the case of a more complete documentation including other soil types, they may be used to construct a more universal solution.

Acknowledgements. This paper benefited from the reviews of Prof. F. van Tol and anonymous reviewer. We are very grateful to reviewers whose comments have led to improvements of the manuscript, also reviewers are thanked for their careful and constructive reviews.

\section{REFERENCES}

Arroyo, M., 2013. Geotechnical profiling and "in-situ" measurement of soil stiffness. Geotechnical and Geophysical Site Characterization, 4:425-434. Taylor \& Francis Group, London.

Atkinson, J.H., 2000. Nonlinear soil stiffness in routine design. Geotechnique, 50: 485-508

Burns, S.E., Mayne, P.W., 2002. Interpretation of seismic piezocone results for the evaluation of hydraulic conductivity in clays. Geotechnical Testing Journal, 25: 333-340.

Jamiolkowski, M., 2012. Role of geophysical testing in geotechnical site characterization. Victor de Mello Lecture, Lisbon, April 2012, Portuguese-Brazilian Geotechnical Congress, Soils and Rocks, 35: 1-21.

Jefferies, M.G., Davies, M.P., 1993. Use of CPTu to Estimate Equivalent SPT N60. Geotechnical Testing Journal, 16: 458-468.

Kim, D.S., Youn, J.U., Park, H.J., 2013. Applications of shear wave velocity on various geotechnical problems. Geotechnical and Geophysical Site Characterization, 4: 661-673.

Lunne, T., Robertson, P.K, Powell, J.J.M., 1997. Cone Penetration Testing in Geotechnical Practice. Blackie Academic \& Professional, London.
Mayne, P.W., 2006. In-Situ Test Calibrations for Evaluating Soil Parameters. Overview Paper on In-Situ Testing, Singapore Workshop, Nov.-Dec. 01st, 2006: 1-56.

Mayne, P.W., 2007. Cone Penetration Testing. A Synthesis of Highway Practice. Transportation Research Board, Washington, D.C., 2007, NCHRP, 368: 117.

Mayne, P.W., Puzrin, A.M., Elhakim, A.F., 2003. Field characterization of small- to high-strain behavior of clays. Soil and Rock America, Proceedings, 12th Pan Am Conference, Verlag Gluckauf, Essen, 1: 307-313.

Robertson, P.K., 2001. Sixty Years of the CPT - How far have we come? Proceedings, International Conference on In-Situ Measurement of Soil Properties and Case Histories, Bali, May 21--24, 2001: 1-16.

Robertson, P.K., 2009. CPT interpretation - a unified approach. Canadian Geotechnical Journal, 46: 1-19.

Sikora, Z., 2006. Sondowanie statyczne (in Polish). Metody i zastosowanie w geoinżynierii. Wydawnictwa NaukowoTechniczne, Warszawa.

Tschuschke, W., Kmiecik, G., Mikos, A., 2013. Profiling in mine tailings based on CPTU and SDMT. Geotechnical and Geophysical Site Characterization, 4: 1701-1706. Taylor \& Francis Group, London. 